AD WATCH

\title{
Tobacco sponsorship of Formula One and CART auto racing: tobacco brand exposure and enhanced symbolic imagery through co-sponsors' third party advertising
}

\author{
T Dewhirst, A Hunter
}

Tobacco Control 2002;11:146-150

Through third party advertising of events such as Formula One and CART auto racing, tobacco brand names continue to attain visibility to a vast audience

See end of article for authors' affiliations

\section{Correspondence to:} Timothy Dewhirst, St John's College, University of British Columbia, 2111 Lower Mall, Suite 1110 , Vancouver, BC V6T 1Z4, Canada;

tdewhirst@hotmail.com
S ponsoring sports events is meant to serve a number of marketing objectives for a corporation and its products, including increasing brand awareness, reinforcing or enhancing brand image, and improving sales or market share. ${ }^{1-4}$ Moreover, tobacco manufacturers have used sponsorship as a means of circumventing advertising regulations or restrictions. Once cigarette advertising was banned from the broadcast media in the UK in 1965, in the USA in 1971, and in Canada in 1972, individual tobacco companies increasingly turned toward sponsoring broadcast sports events to compensate for lost advertising exposure. $^{5-7}$ Despite cigarette advertising not being permitted on television in such countries, auto racing sponsorship serves as a particularly good example of how tobacco companies continuously gain widespread exposure for their respective brands. Citing Sponsors Report, it has been reported that Marlboro received nearly 3.5 hours of in-focus exposure during the 15 races of the 1989 Championship Auto Racing Teams (CART) season and a videotape recording of the Marlboro Grand Prix on 16 July 1989 revealed that Marlboro was seen or mentioned 5933 times. $^{8}$ More recently, Sponsors Report data indicate that from 1997 through 1999 tobacco companies achieved 169 hours of television advertising exposure through sponsoring motor sports events held in the USA, which was estimated to be equivalent to US\$411 million in advertising value. ${ }^{9}$

Additional objectives for sport sponsorship are cross-promotional/co-sponsorship opportunities, as well as enhancement of trade relations and goodwill. ${ }^{2410}$ Tobacco companies are seldom the exclusive sponsors of an event or team, and in the case of auto racing, multiple sponsors are inevitable considering the exorbitant operating budgets that characterise the sport. Scuderia Ferrari Marlboro, McLaren Mercedes, and British American Racing (BAR) Honda represent the Formula One (F1) racing teams with the largest budgets for the 2001 season, spending \$284.4 million, $\$ 274.6$ million, and $\$ 194.5$ million, respectively. ${ }^{11}$ Although there is a long list of sponsors for each of these teams, tobacco companies represent a particularly significant source of funding. Philip Morris, in its partnership with Ferrari, spends roughly \$23 million each year toward race car driver Michael Schumacher's salary, and about \$65 million toward having Marlboro placed in multiple locations of the race car, helmet, and overalls of Schumacher and his team mate Rubens Barrichello. ${ }^{1213}$ German cigarette manufacturer Reemtsma, through its West brand, is a key sponsor of the McLaren team, spending \$37 million annually for similar sponsor name locations. ${ }^{13}$ British American Tobacco, as the primary backer of BAR, contributed about $\$ 47$ million during the 2000 season. ${ }^{14}$ Collectively, tobacco manufacturers annually spend \$250 million toward Fl teams. ${ }^{15}$

Strategic alliances or partnerships formed with auto racing co-sponsors provide tobacco manufacturers with opportunities to attain visibility and exposure for their respective brands through co-sponsors' third party advertising. In such advertising, the symbolic imagery that is linked with particular cigarette brand names may be enhanced when surrounded by other products possessing similar desired symbolic qualities. Third party advertising potentially serves a third purpose since co-advertisers in some cases share the advertising costs, permitting each respective company to get a greater bang for their buck (that is, given a set budget, a greater number of exposures are achieved).

To demonstrate the primary purposes fulfilled by third party advertising, this paper draws from marketing literature on sponsorship objectives (including the benefits and disadvantages of being a co-sponsor of racing properties), cites examples from news and trade sources, and utilises interviews with two senior advertising practitioners who have worked on tobacco accounts. While this paper focuses on the dynamics of co-sponsorship in $\mathrm{Fl}$ auto racing and, to a lesser extent, CART auto racing, the general concepts are applicable to other types of motor sports sponsored by tobacco corporations, including the Indy Racing League, the National Association of Stock Car Racing (NASCAR) series, and the National Hot Rod Association (NHRA) series.

\section{TOBACCO EXPOSURE THROUGH THIRD PARTY ADVERTISING}

Cigarette brand names are visible through the promotion of unrelated products, which are auto racing co-sponsors. A 1990 Philip Morris document acknowledged that, in Taiwan, they had "developed an [Fl] alliance with TAG Heuer watches, whereby TAG Heuer places print as well as outdoor advertising, two restricted mediums, 


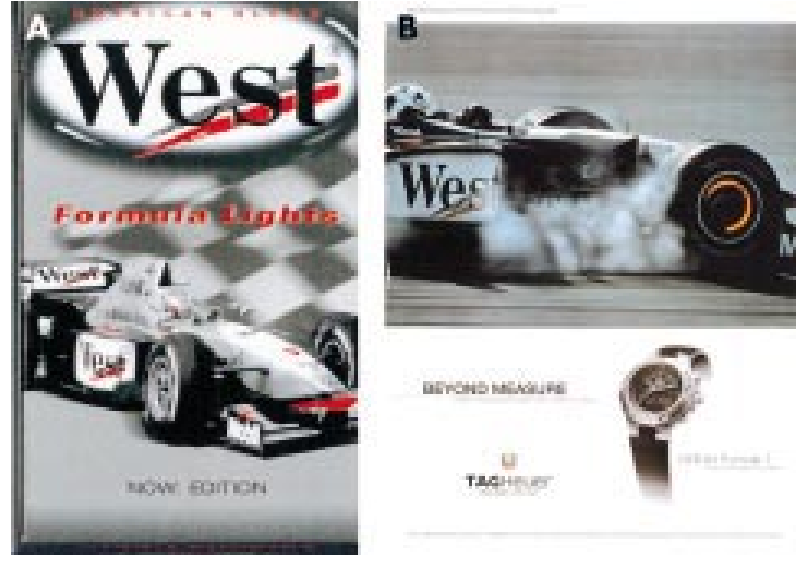

Figure 1 Cigarette package graphics (left) and TAG Hever/West advertisement (right). Source: West cigarettes were purchased at a duty free shop at Gatwick airport in London, UK on 16 July 200 1; advertisement was featured in Maclean's, Canada's weekly news magazine, 4 June 2001

in which our car is prominently featured. Newspaper circulation alone exceeded 2 million". ${ }^{16}$ Like Philip Morris, Swiss watch manufacturer TAG Heuer has been a long time Fl sponsor. TAG Heuer has provided timing services for Fl auto racing events since 1969, initiated its timekeeping assistance to the Fl Ferrari race team in 1971, and has acted as the official timekeeper of the F1 championships since 1992. ${ }^{17}$

TAG Heuer is now a partner of the McLaren race team, and as a result of this partnership, West is a cigarette brand presently attaining exposure through third party advertising (fig 1). According to the watch manufacturer's website, "in 2001, TAG Heuer is naturally pursuing its privileged partnership with West McLaren Mercedes". TAG Heuer currently supports a few select athletes and among them are McLaren Fl drivers Mika Hakkinen and David Coulthard.

Honda, Hewlett-Packard, and Molson represent additional companies that have repeatedly engaged in third party advertising for tobacco manufacturers. Honda is a technical partner and engine supplier for the BAR and Jordan Fl teams. ${ }^{15}$ With Lucky Strike and Benson and Hedges as respective cosponsors of these teams, the cigarette brands have been gaining significant visibility through Honda promotions (fig 2). Honda is also the engine supplier for the Marlboro Penske and KOOL Green CART teams, and through feature articles on the race teams in its custom magazine Velocity, has provided exposure for the Marlboro and KOOL brands. ${ }^{18}$

Hewlett-Packard has been a Jordan sponsorship partner and technology provider since 1990, the year the Jordan team began racing in Fl. ${ }^{19}$ Hewlett-Packard has engaged in advertising that not only gives visibility to Benson and Hedges, but surprisingly uses the colours linked with Benson and Hedges packaging as opposed to the colours representative of their own company (fig 3).

As a final but not exhaustive example, advertising for Canada's largest producer of beer, Molson Breweries, has given visibility to the Canadian cigarette brand, Player's (fig 4). The Molson Take Care advertisement from 1998 features CART auto racing driver Greg Moore, who at the time was sponsored by Player's, but died in 1999 as a result of a crash during the Marlboro 500 race. While Moore is depicted in his racing gear with the racing car alongside, the ad copy states, "This isn't a racing poster. It's a don't be stupid poster. Don't drink $\delta$ drive". There is a certain level of irony associated with this promotion since the message is to act responsibly, yet a cigarette brand is represented.

Both Molson and Player's have been long time sponsors of Indy car racing (now known as CART racing) in Canada. Molson is the title sponsor of CART races held in Toronto and Van-

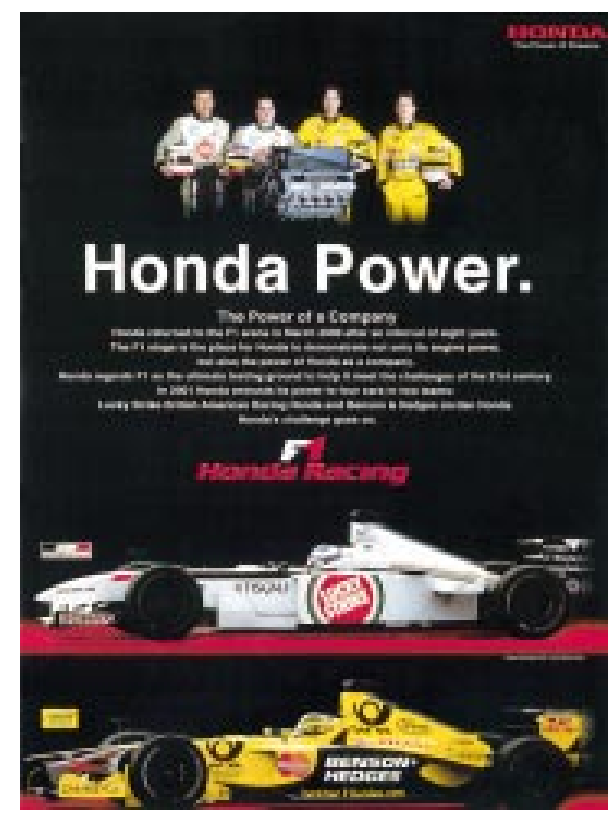

Figure 2 Honda advertisement, with Lucky Strike and Benson and Hedges depicted. Source: Formula 1 Magazine, May 2001.

couver, which were founded in 1986 and 1990, respectively. Player's began to sponsor auto racing in Canada in 1961 and currently supports CART drivers, Patrick Carpentier and Alex Tagliani. ${ }^{20}$ Player's and beer brand Molson Canadian were partners for the recent canada.com Ultimate Racing Challenge, which gave contestants a chance to win authentic racing gear or a trip to Australia with Patrick Carpentier or Alex Tagliani. ${ }^{21}{ }^{22}$ Alongside with Molson Canadian, Player's is a primary sponsor of the Molson Indy CART races.

\section{ENHANCEMENT OF TOBACCO IMAGERY THROUGH CO-BRANDING}

Sponsorship provides co-branding opportunities, which may enrich the symbolic value of cigarette brands, as well as that of their co-sponsors. Co-branding is defined as placing two or more brand names on a product, its package, or additional elements of the promotional mix..$^{23}$ The objectives of cobranding are best realised if the associations of each brand are strong and complementary. ${ }^{24}$ The associations among brands are strengthened if there has been a long standing relationship and it is well promoted. According to the president of Co-Options, a US firm that specialises in seeking out co-op marketing prospects: "We want to be matchmakers for brands, but we don't want these to be flings. Our goal is to build longterm relationships that last at least a few years, giving brands maximum benefit from connections with other marketers and brands." ${ }^{25}$ TAG Heuer and McLaren (with West cigarettes being a co-sponsor), for example, have been partners since 1985 .

The complementarities of brands, meanwhile, may be based on either their functional or symbolic properties. From the perspective of tobacco manufacturers promoting a particular brand, co-sponsors (and co-advertisers) should ideally include products or services with complementary functions, brand images, or identities. A promotion featuring Marlboro cigarettes and a Zippo lighter would exemplify co-advertisers serving complementary functions (that is, how the products may be used together). Applying this concept to Fl co-sponsors, the Tic Tac and Marlboro logos were located sideby-side on the helmet, upper arm, and racing car livery of Michael Schumacher during the 2001 season, whereby consumers were reminded that the mints could be used to combat bad breath resulting from smoking. With respect to 


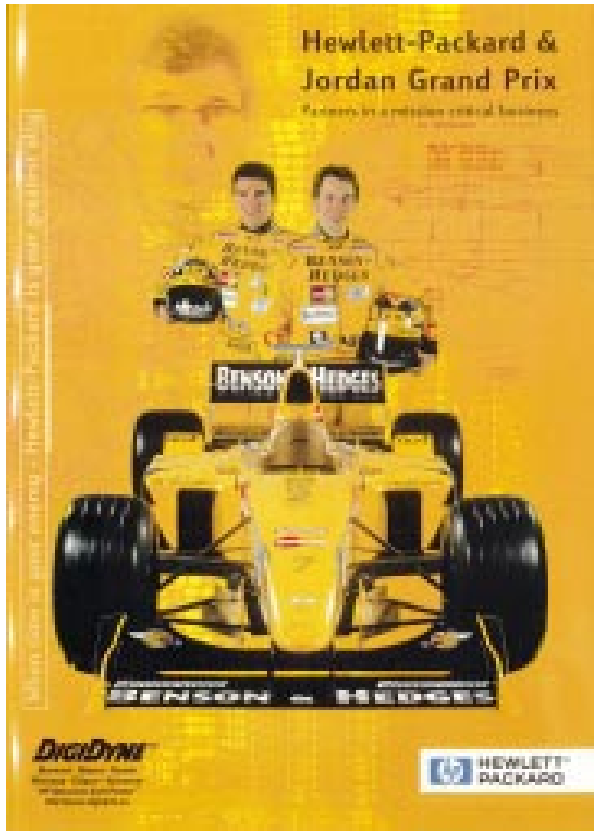

Figure 3 Hewlett-Packard/Benson and Hedges advertisement. Source: Fl Racing, July 1999.

symbolic properties, Budweiser beer represents a suitable complement to Marlboro since both brands have consistently been linked with macho, rugged, and independent dimensions in promotions. Such brand matching observations are consistent with McCracken's concept of "Diderot unities" which emphasises that the meaning of goods is largely determined by their relationship to other goods. ${ }^{26}$ According to McCracken: "The meaning of a good is best (and sometimes only) communicated when this good is surrounded by a complement of goods that carry the same significance. Within this complement, there is sufficient redundancy to allow the observer to identify the meaning of the good."

The symbolic complementarities of goods help explain why several companies would tolerate an association between their products and a controversial item such as cigarettes. TAG Heuer watches, for example, are positioned as a luxury brand, and have accordingly been linked with dimensions such as prestige, innovation, quality, precision, success, excellence, performance, and popularity (worldwide recognition)..$^{17}$ With a long history of success and excellence demonstrated, Ferrari Marlboro and West McLaren Mercedes would be seen as appropriate Fl teams to sponsor (both teams share the record of holding 11 drivers' titles). ${ }^{27}$ The cigarette brands, meanwhile, gain credibility by being linked with less contentious products.

\section{LOGISTICS OF CO-ADVERTISING: INSIGHTS FROM SENIOR ADVERTISING PRACTITIONERS*}

When tobacco branding appears prominently in advertisements for other auto racing sponsors, it is typically the result of pre-existing agreements between a racing team and its individual sponsors, formalised in the sponsorship contract.

\footnotetext{
*This section is largely based on the findings from three separate interviews. A phone interview was conducted with Peri Luel, vice-president of partnership programmes for Molstar Sports and Entertainment, on 26 October 2001. Two senior advertising practitioners-who requested that their names be withheld-were interviewed through email correspondence on 16 October 2001 and 18 October 2001.
}

Racing sponsors are often bound by the terms of their sponsorship deals to use official team photographs in any piece of communication that exploits their connection to the world of motor sports. At the very least, teams ask for final approval of the advertising, which can be withheld if other sponsors are being treated unfairly. Approved images clearly display the names or logos of team sponsors, and this is especially true in the case of key sponsors who occupy the most "real estate" on the cars and other team assets. According to one senior advertising and promotions practitioner, who has worked on major tobacco brands in the Canadian market for the past several years: "Sponsorship agreements and accompanying rights govern everything ... .I can't see any one sponsor having the right to adjust or alter any image, as it would impact on the rights of the others." Consequently, brands such as TAG Heuer, Honda, and Hewlett-Packard enter an odd creative relationship with tobacco brands, with their one degree of separation being the racing property itself.

Tobacco marketers would not likely initiate this creative relationship, although they would warmly welcome it in most cases, and it is anticipated and encouraged to some extent in the design of the sponsorship deals. Peri Luel, vice-president of partners' programmes at Molstar Sports and Entertainment which manages major racing events such as the Molson Indy, explains that while co-branding "is not one of the factors that get played up significantly [in sponsorship offerings], it's inherently part of it". Luel declined any comment on Molstar's dealings with the tobacco industry, but his remarks support the understanding that the tobacco companies' orientation to their co-sponsors is opportunistic rather than proactive. It is unlikely that tobacco companies would offer or be invited to share production or media costs for this kind of third party advertising; there are strong political and perceptual reasons for these creative partners to stay at arm's length. The advertising and promotions practitioner quoted at the beginning of this section acknowledges that tobacco marketers will "go for a ride on anything they can", but goes on to explain that any exchange of money to help cover advertising costs "would be extremely risky for the tobacco company to be involved in. The fallout with the public and legislators would not be worth it ...they have enough problems staying out of trouble on their own. [The tobacco company and the primary advertiser] would probably be the recipients of adverse synergy: $1+1=$ more than twice the heat." This appears to have been the case in June 2001, when both TAG Heuer and Reemtsma, the maker of West cigarettes, were scrutinised by the French publication Le Monde after West branding elements appeared in a TAG Heuer billboard that featured an Fl car (as seen in fig 1). ${ }^{28}$ TAG Heuer was accused in the press of violating French laws governing tobacco advertising, and defended itself by saying that as a McLaren Mercedes sponsor it was required to use official team images.

In a climate of increasing regulation and scrutiny of tobacco marketing, other corporate players in the racing environment are not eager to be seen as tobacco's willing co-conspirators and risk doing damage to their own valuable brands. Brand managers at large established firms are understandably risk adverse, and they incur some risk already by complying with sponsorship guidelines regarding use of images, as the TAG Heuer controversy shows. A senior strategic planner at a major Canadian advertising agency, with tobacco experience in the UK, speculates on the advertiser's position: "A good partnership is where each party brings positive value to the other ...I don't think TAG, for example, would respond well to a tobacco company coming to them with the thought of a joint programme. TAG wanted the association with motor sports, and the tobacco logos came along with that. Of course the tobacco company would have been very happy about this."

The two advertising industry sources quoted in this paper cannot point to even one example of traditionally planned co-branded advertising activity that includes a tobacco brand, 


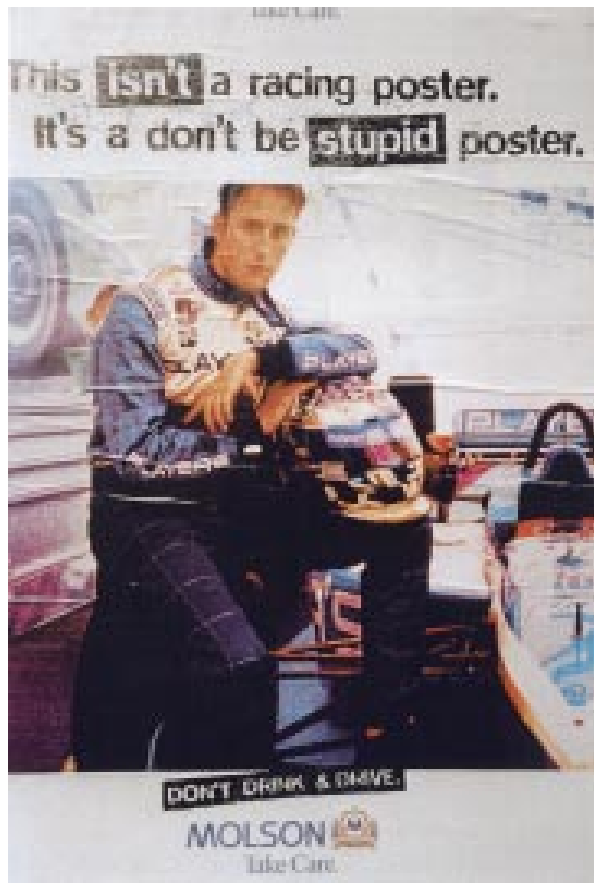

Figure 4 "This isn't a racing poster. It's a cigarette poster." Molson Take Care/Player's advertisement located at a street-side in Vancouver, Canada. Source: photograph by Timothy Dewhirst.

but the third party advertising that emerges from sponsorship must be recognised as a form of co-branding, despite the fact that it is not a consensual act between like minded corporate partners. In the moment of viewing a poster, print piece, or billboard, most consumers will not speculate or care about the process behind it, or make a distinction between active and passive partnerships. The end result is the same. Sponsorship creates a unique advertising space in this way-relationships develop between brands that would never have been possible through open, direct negotiation because of the serious public relations risks involved for all parties.

A final factor in understanding third party tobacco advertising is the art director's point of view. Credibility is an important agency consideration when the creative goal is to exploit a brand's connection with racing as much as possible; according to Peri Luel of Molstar, maximum leverage of the property is the core lesson of "Sponsorship Marketing 101". This principle in action has potential advantages for tobacco marketers, because tobacco branding has been strongly associated with motor sports for many years, and to avoid showing it in a racing advertisement might under some circumstances be perceived by the professionals who create these ads as slightly jarring to the target consumer (that is, undermining rather than reinforcing the advertiser's connection with the sport). Even if the sponsorship contract permitted it, a digitally altered or "cleaned up" car would not, from the perspective of the agency creative department, be as compelling an image as the real thing-cluttered, colourful, and in many cases (depending on the racing team and circuit) displaying a tobacco message.

\section{CONCLUSION}

Through third party advertising, tobacco brand names continue to attain visibility and the symbolic value of the brands are further enriched as a result of surrounding product complements. While cost efficiencies may also be fulfilled through third party advertising and co-branding activities, the senior advertising practitioners interviewed for this paper consistently maintained that tobacco companies are highly unlikely to assist with the costs of such advertising. Considering the long standing, dominant presence of tobacco companies in motor sports, however, the advertising practitioners continued by claiming that many co-sponsors likely depict tobacco livery in their advertising in an effort toward being "authentic" and to adhere to the stipulations outlined in sponsorship contracts. As tobacco sponsorship becomes less commonplace in auto racing as a result of newly implemented policies within many jurisdictions, it will be important to monitor that the prevalence of tobacco imagery depicted in advertising declines accordingly.

Third party advertising, much like sponsoring broadcast sport events, represents an opportunity for tobacco manufacturers to circumvent tobacco promotion regulations. As tobacco control policies are developed, such loopholes need to be anticipated and accounted for. What remains problematic, however, are jurisdictional issues. When the European Commission stipulated that tobacco sponsorships in Fl would be banned in 2006, for example, it was threatened that races might be moved out of Europe and held in alternative locations such as China, South Korea, and Indonesia (where restrictions on tobacco promotion are much less severe). ${ }^{29}$ Since domestic bans on tobacco sponsorship are typically not applicable to foreign media imported or transmitted into the respective country, many of Fl's 300 million television viewers watching each race would remain exposed to tobacco promotions. $^{30}$ In light of such opportunities to exploit loopholes, a global treaty that deals with transnational and transborder dimensions of tobacco promotion appears justified.

\section{ACKNOWLEDGMENTS}

The authors would like to thank Richard Pollay for his helpful comments and financial assistance toward this project. John Slade and Raychel Kubby Adler were also generous, providing the authors with additional examples of third party advertising. Timothy Dewhirst is a recipient of a National Health PhD Fellowship from Health Canada/Canadian Institutes of Health Research.

\section{Authors' affiliations}

T Dewhirst, University of British Columbia, Vancouver, BC, Canada

A Hunter, BBDO Toronto, Toronto, Ontario, Canada

\section{REFERENCES}

1 Cornwell TB, Maignan I. An international review of sponsorship research. Journal of Advertising 1998;27:1-21.

2 Irwin RL, Sutton WA. Sport sponsorship objectives: an analysis of their relative importance for major corporate sponsors. European Journal of Sport Management 1994;1:93-101.

3 Otker T. Exploitation: the key to sponsorship success. European Research 1988; 16:77-86.

4 Irwin R, Asimakopoulos M. An approach to the evaluation and selection of sport sponsorship proposals. Sport Marketing Quarterly 1992;1:43-51.

5 Warner KE. Clearing the airwaves: the cigarette ad ban revisited. Policy Analysis 1979;5:435-50.

6 Ledwith F. Does tobacco sports sponsorship on television act as advertising to children? Health Educ J 1984;43:85-8.

7 Stoner RH. 200 mph cigarette ads: a comparison of international restrictions on tobacco sports sponsorship. Hastings International and Comparative Law Review 1992;15:639-70.

8 Blum A. The Marlboro Grand Prix: circumvention of the television ban on tobacco advertising. N Engl J Med 1991;324:913-7.

9 Siegel M. Counteracting tobacco motor sports sponsorship as a promotional tool: is the Tobacco Settlement enough? Am J Public Health 2001;91:1100-6.

10 Copeland R, Frisby W, McCarville R. Understanding the sport sponsorship process from a corporate perspective. Journal of Sport Management 1996;10:32-48.

11 Anon. Ferrari's budget for season is $\$ 284$ million. Formula 1 Magazine 2001 March;1:24.

12 Anon. Schumacher set to sign $\$ 36 \mathrm{~m}$ deal for Ferrari. Formula 1 Magazine 2001 March;1:21.

13 Saward J. Money matters to sponsors - but who gets the best bang for their bucks? Grand Prix International 2001 Spring; 1:140-3.

14 Donaldson G. Failure is no longer an option. Formula 1 Magazine 2001 March;1:170-2. 
15 Grange M. Win on Sunday ... sell on Monday. R.O.B. Magazine 2001 August; 1 8:36-40

16 Anon. Marlboro 1990. Philip Morris. Circa 1990. URL: www.pmdocs.com/getallimg.asp? DOCID $=2504034844 / 4875$. Bates No. 2504034852:9.

17 Anon. TAG Hever website. Online www.tagheuer.com/share. Accessed 3 August 2001 [see sections titled The Brand, Sponsorship, Advertising, Sports, Formula 1, Partners, and History].

18 Proffit A. Family matters. Velocity: Journal of the Honda-Acura Club 2000 Fall;2:24-8 [also see photographs on pages 3, 19, 30 for tobacco brand name exposure]

19 Anon. The power behind fl jordan.com. Fl Racing 2000 September:58-9.

20 Dewhirst T, Sparks R. Intertextuality, tobacco sponsorship of sports, and adolescent male smoking culture: a selective review of tobacco industry documents. Journal of Sport and Social Issues 2003;27:(in press).

21 Anon. Are you up to the Challenge? The Vancouver Sun 21 August 2001:C5 [Ultimate Racing Challenge advertisement featuring Alex Tagliani].

22 Anon. Are you up to the Challenge? The Vancouver Sun 28 August 2001:C4 [Ultimate Racing Challenge advertisement featuring Patrick Carpentier].
23 Lamb Jr CW, Hair Jr JF, McDaniel C. Marketing, 5th ed. Cincinnati: South-Western College Publishing, 2000.

24 Aaker DA, Joachimsthaler E. Brand leadership. New York: The Free Press, 2000.

25 Fitzgerald K. Brands wed marketing plans. Advertising Age 1994 October 17;65:30

26 McCracken G. Culture and consumption. Bloomington and Indianapolis: Indiana University Press, 1988:121

27 Starcevic N. Schumacher best again. The Vancouver Sun 20 August 2001:D5

28 Anon. En France, les cigarettiers adoptent la publicité subliminale [In France, cigarette companies adopt subliminal advertising]. Le Monde 10-11 June 2001:14.

29 Wilson R. Race against time: sponsors have a lot of influence in the world of motor racing, but can companies such as BAT find a way to beat the threatened worldwide ban on Formula One's tobacco sponsorship? Marketing Week 1999 January 21;21:51-3.

30 Hawaleshka D. Grand prix wizardry. Maclean's 2001 June $25 ; 114: 40-1$

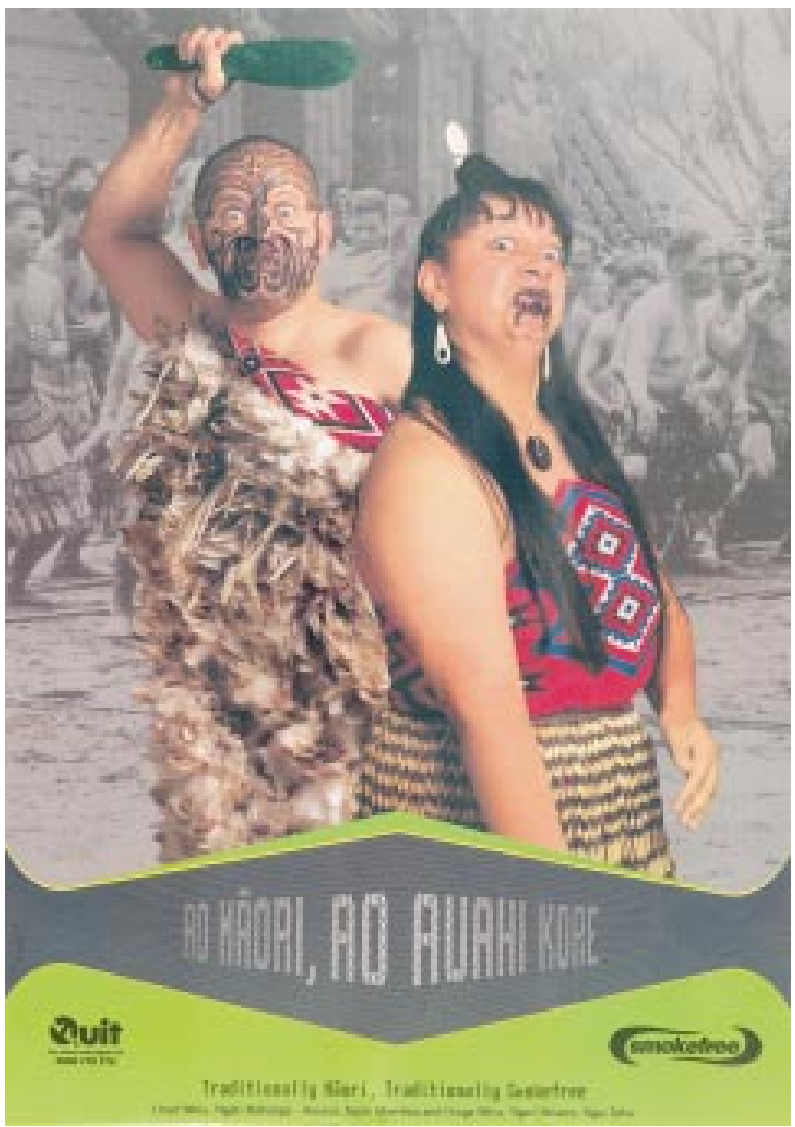

Ao Maori, Ao Auahi Kore (Traditionally Maori, traditionally

Smokefree)-recapturing the traditional Smokefree status of Maori, the indigenous people of New Zealand. Auahi Kore (Smokefree Maori) poster produced by the Health Sponsorship Council of New Zealand. www.healthsponsorship.co.nz 